\title{
Oxidation of Reduced Sulfur Species: Carbonyl Sulfide
}

\author{
PETER GLARBORG, ${ }^{1}$ PAUL MARSHALL ${ }^{2}$ \\ ${ }^{1}$ Department of Chemical and Biochemical Engineering, Technical University of Denmark, DK-2800 Kgs. Lyngby, Denmark \\ ${ }^{2}$ Department of Chemistry and Center for Advanced Scientific Computing and Modeling (CASCaM), \\ University of North Texas, Denton, TX 76203-5017
}

Received 25 October 2012; revised 15 January 2013; accepted 15 January 2013

DOI 10.1002/kin.20778

Published online 25 April 2013 in Wiley Online Library (wileyonlinelibrary.com).

\begin{abstract}
A detailed chemical kinetic model for oxidation of carbonyl sulfide (OCS) has been developed, based on a critical evaluation of data from the literature. The mechanism has been validated against experimental results from batch reactors, flow reactors, and shock tubes. The model predicts satisfactorily oxidation of OCS over a wide range of stoichiometric air-fuel ratios $(0.5 \leq \lambda \leq 7.3)$, temperatures (450-1700 K), and pressures (0.02-3.0 atm) under dry conditions. The governing reaction mechanisms are outlined based on calculations with the kinetic model. The oxidation rate of OCS is controlled by the competition between chain-branching and -propagating steps; modeling predictions are particularly sensitive to the branching fraction for the OCS + O reaction to form $\mathrm{CO}+\mathrm{SO}$ or $\mathrm{CO}_{2}+\mathrm{S}$. (C) 2013 Wiley Periodicals, Inc. Int J Chem Kinet 45: 429-439, 2013
\end{abstract}

\section{INTRODUCTION}

Reduced sulfur species such as $\mathrm{H}_{2} \mathrm{~S}$, carbonyl sulfide (OCS), and $\mathrm{CS}_{2}$ are formed in thermal conversion of solid fuels such as coal and biomass, and they are important as reactants or by-products in a number of industrial processes, such as the recovery of sulfur from acid gases. Interest in sulfur chemistry in combustion [1], in industrial processes such as the Claus process [2], and in the atmosphere [3] has lead to extensive research in sulfur chemistry. Much of the work has been motivated by emissions and operational issues

\footnotetext{
Correspondence to: Peter Glarborg; e-mail: pgl@ kt.dtu.dk Supporting Information is available in the online issue at www.wileyonlinelibrary.com.

(C) 2013 Wiley Periodicals, Inc.
}

related to the Claus process [2,4-8]. While the thermal conversion and sulfidation of $\mathrm{H}_{2} \mathrm{~S}$ have received considerable attention [9-15], in fact OCS and $\mathrm{CS}_{2}$ can contribute up to $20 \%$ to the sulfur emissions from Claus plants [6]. Understanding the kinetics of the formation and consumption of OCS and $\mathrm{CS}_{2}$ in the front end of the Claus process will be a significant step toward reducing the environmental impact of these plants [5]. Despite the research in sulfur chemistry, the detailed kinetics of the thermal conversion of OCS and $\mathrm{CS}_{2}$ are still in question. The early work was reviewed in 1972 by Cullis and Mulcahy [16]. Significant progress has been made since then, but the complexities of the sulfur chemistry, as well as the experimental challenges including a high sensitivity toward surfaces, have prevented the establishment of a validated, comprehensive reaction mechanism for oxidation of reduced sulfur species. 
The simplest of the reduced sulfur species is OCS. OCS is formed in gasification of coal [17], in chemical looping combustion of coal [18], and in biomass pyrolysis [19]. In the recovery of sulfur from acid gases, OCS can be formed from oxidation of $\mathrm{CS}_{2}$ [4] or from reaction of $\mathrm{H}_{2} \mathrm{~S}$ with carbon oxides [6]. Thermal decomposition and oxidation of OCS have been studied in batch reactors [20-23], flow reactors [4,5,24], shock tubes [25-34], and laminar premixed flames [35-39]. Detailed chemical kinetic modeling of OCS oxidation has mostly been limited to shock tube conditions, simulating ignition delays [28], or atomic $\mathrm{S}$ or $\mathrm{O}$ profiles [29,31-34] in $\mathrm{OCS} / \mathrm{O}_{2} / \mathrm{Ar}$ mixtures.

The objective of the present study is to develop a detailed chemical kinetic model for oxidation of OCS. Important kinetic parameters are drawn mostly from experimental determinations or recent theoretical work. The resulting model is validated against data from batch reactors, flow reactors, and shock tubes from the literature and used to analyze OCS oxidation pathways and rate-limiting steps over a wide range of conditions.

\section{DETAILED KINETIC MODEL}

In the present study, the starting mechanism and corresponding thermodynamic properties were drawn from earlier work by the authors on oxidation of $\mathrm{CO} / \mathrm{H}_{2}$ [40] and on sulfur chemistry [41-47]. The OCS oxidation subset of the mechanism was developed in the present work. The thermodynamic properties for selected species in the sulfur subset are shown in Table I. The data were drawn from the Goos et al. database [48], except for the properties of $\mathrm{OCS}_{2}$ [49].

Table II lists the key reactions in the OCS oxidation scheme with the rate coefficients used in the present work. The full mechanism is available as supplemen- tal material. The published experimental data on OCS oxidation are largely obtained under conditions with at most trace concentrations of water vapor. For this reason, the important radicals are $\mathrm{O}, \mathrm{S}$, and $\mathrm{SO}$, while chain carriers such as $\mathrm{H}, \mathrm{OH}, \mathrm{HO}_{2}$, and $\mathrm{SH}$ have at most a minor influence. In industrial processes, however, OCS is typically formed in gases that also contain $\mathrm{H}_{2} \mathrm{~S}$, and we have chosen to include in the mechanism species and chain carriers involving hydrogen, even though this part of the model could not be validated. The formation of carbon sulfides has been disregarded, since the $\mathrm{C}=\mathrm{O}$ bond in OCS is too strong to be broken under the conditions of interest in this study.

The thermal dissociation of OCS proceeds by $\mathrm{S}$ elimination:

$$
\mathrm{OCS}+\mathrm{M} \rightleftharpoons \mathrm{CO}+\mathrm{S}+\mathrm{M}
$$

An Arrhenius plot for the reaction is shown in Fig. 1. It has been characterized in a number of shock tube studies [25,26,30,32,34], which are in good agreement. We have adopted the rate constant for (R1) from the work of Oya et al. [32]. Remarkably, a linear extrapolation of the rate constant of Oya et al. (1900-3230 $\mathrm{K})$ to the conditions of the batch reactor work of Partington and Neville [23] (823-873 K) shows agreement within a factor of two.

Reactions of OCS with the $\mathrm{O} / \mathrm{H}$ radical pool have been studied both experimentally and theoretically. The rate constant for the reaction with atomic hydrogen

$$
\mathrm{OCS}+\mathrm{H} \rightleftharpoons \mathrm{CO}+\mathrm{SH}
$$

has been measured at low temperatures by Rommel and Schiff [60], Tsunashima et al. [61], and Lee et al. [62], and at high temperatures (1170-1830 K) by Woiki and Roth [63]. In addition, the reaction has been studied theoretically by Rice et al. [64] and very recently by

Table I Thermodynamic Properties of Selected Species in the Reaction Mechanism

\begin{tabular}{lrrrrrrrrrr}
\hline Species & $\mathrm{H}_{298}$ & $\mathrm{~S}_{298}$ & $\mathrm{C}_{p, 300}$ & $\mathrm{C}_{p, 400}$ & $\mathrm{C}_{p, 500}$ & $\mathrm{C}_{p, 600}$ & $\mathrm{C}_{p, 800}$ & $\mathrm{C}_{p, 1000}$ & $\mathrm{C}_{p, 1500}$ & Ref. \\
\hline $\mathrm{OCS}$ & -33.86 & 55.35 & 9.95 & 10.96 & 11.68 & 12.22 & 13.02 & 13.56 & 14.27 & {$[48]$} \\
$\mathrm{SO}$ & 1.20 & 53.04 & 7.21 & 7.55 & 7.84 & 8.08 & 8.42 & 8.62 & 8.95 & {$[48]$} \\
$\mathrm{SO}_{2}$ & -70.94 & 59.31 & 9.54 & 10.40 & 11.13 & 11.72 & 12.53 & 13.02 & 13.61 & {$[48]$} \\
$\mathrm{S}$ & 66.19 & 40.11 & 5.66 & 5.57 & 5.44 & 5.32 & 5.21 & 5.13 & 5.06 & {$[48]$} \\
$\mathrm{S}_{2}$ & 30.68 & 54.56 & 7.77 & 8.12 & 8.36 & 8.52 & 8.71 & 8.91 & 9.29 & {$[48]$} \\
$\mathrm{SH}$ & 34.18 & 46.78 & 7.75 & 7.61 & 7.49 & 7.44 & 7.61 & 7.83 & 8.34 & {$[48]$} \\
$\mathrm{OCS}_{2}$ & 6.17 & 66.85 & 14.03 & 15.45 & 16.43 & 17.12 & 17.97 & 18.50 & 19.19 & {$[49], \mathrm{pw}$} \\
\hline
\end{tabular}

Units are $\mathrm{kcal} \mathrm{mol}^{-1}$ for $\mathrm{H}$, and cal $\mathrm{mol}^{-1} \mathrm{~K}^{-1}$ for $\mathrm{S}$ and $\mathrm{C}_{p}$.

The temperature $(\mathrm{T})$ range is in $\mathrm{K}$.

"pw" denotes present work.

The heat of formation for $\mathrm{OCS}_{2}$, as well as rotational constants and frequencies to calculate entropies and heat capacities, was derived from the computational results of $\mathrm{Lu}$ et al. [49]. 
Table II Reaction Subset for Carbon Disulfide Oxidation

\begin{tabular}{|c|c|c|c|c|c|}
\hline & Reaction & $\begin{array}{c}A \\
(\mathrm{~cm}, \mathrm{~mol}, \mathrm{~s})\end{array}$ & $\beta$ & $\begin{array}{c}E \\
\text { (cal/mol) }\end{array}$ & Source \\
\hline 1 & $\mathrm{OCS}+\mathrm{M} \rightleftharpoons \mathrm{CO}+\mathrm{S}+\mathrm{M}$ & $2.5 \mathrm{E} 14$ & 0.000 & 61,400 & {$[32]$} \\
\hline 2 & $\mathrm{OCS}+\mathrm{H} \rightleftharpoons \mathrm{CO}+\mathrm{SH}$ & $2.2 \mathrm{E} 11$ & 1.022 & 5,584 & {$[50]$} \\
\hline 3 & $\mathrm{OCS}+\mathrm{O} \rightleftharpoons \mathrm{CO}+\mathrm{SO}$ & $\begin{array}{r}4.7 \mathrm{E} 13 \\
-2.0 \mathrm{E} 13\end{array}$ & $\begin{array}{l}0.000 \\
0.000\end{array}$ & $\begin{array}{l}5,200 \\
7,385\end{array}$ & See the text ${ }^{a}$ \\
\hline 4 & $\mathrm{OCS}+\mathrm{O} \rightleftharpoons \mathrm{CO}_{2}+\mathrm{S}$ & $2.0 \mathrm{E} 13$ & 0.000 & 7,385 & See the text \\
\hline 5 & $\mathrm{OCS}+\mathrm{OH} \rightleftharpoons \mathrm{CO}_{2}+\mathrm{SH}$ & 4.6E11 & 0.000 & 16,040 & {$[50]$} \\
\hline 6 & $\mathrm{OCS}+\mathrm{O}_{2} \rightleftharpoons \mathrm{CO}+\mathrm{SO}_{2}$ & $1.0 \mathrm{E} 12$ & 0.000 & 32000 & Estimated as $\mathrm{CS}_{2}+\mathrm{O}_{2}$ \\
\hline 7 & $\mathrm{OCS}+\mathrm{S} \rightleftharpoons \mathrm{CO}+\mathrm{S}_{2}$ & 4.0E04 & 2.570 & 2,345 & {$[49]$} \\
\hline \multirow[t]{4}{*}{8} & \multirow[t]{4}{*}{$\mathrm{OCS}+\mathrm{S} \rightleftharpoons \mathrm{OCS}_{2}$} & $4.6 \mathrm{E} 33$ & -8.220 & 9,476 & $0.066 \mathrm{~atm}[49]^{a}$ \\
\hline & & $1.1 \mathrm{E} 31$ & -6.980 & 8,357 & $0.066 \mathrm{~atm}$ \\
\hline & & 2.4E34 & -8.220 & 9,476 & $0.66 \mathrm{~atm}^{a}$ \\
\hline & & 5.7E31 & -6.980 & 8,357 & $0.66 \mathrm{~atm}$ \\
\hline 9 & $\mathrm{OCS}+\mathrm{SH} \rightleftharpoons \mathrm{CS}_{2}+\mathrm{OH}$ & $1.2 \mathrm{E} 12$ & 0.000 & 51,000 & Estimated as $\mathrm{SH}+\mathrm{CO}_{2}\left(k_{5 \mathrm{~b}}\right)$ \\
\hline 10 & $\mathrm{OCS}+\mathrm{SO} \rightleftharpoons \mathrm{CO}+\mathrm{S}_{2} \mathrm{O}$ & $2.0 \mathrm{E} 12$ & 0.000 & 37,700 & See the text \\
\hline 11 & $\mathrm{~S}+\mathrm{H}+\mathrm{M} \rightleftharpoons \mathrm{SH}+\mathrm{M}$ & $6.2 \mathrm{E} 16$ & -0.600 & 0 & [14] estimated \\
\hline 12 & $\mathrm{~S}+\mathrm{H}_{2} \rightleftharpoons \mathrm{SH}+\mathrm{H}$ & $1.4 \mathrm{E} 14$ & 0.000 & 19,300 & {$[11]$} \\
\hline 13 & $\mathrm{SH}+\mathrm{O} \rightleftharpoons \mathrm{SO}+\mathrm{H}$ & 4.3E11 & 0.724 & $-1,027$ & [51] \\
\hline \multirow[t]{2}{*}{14} & \multirow[t]{2}{*}{$\mathrm{SH}+\mathrm{O} \rightleftharpoons \mathrm{SO}+\mathrm{H}$} & $1.8 \mathrm{E} 12$ & 0.000 & 0 & \multirow[t]{2}{*}[51]{$^{a}$} \\
\hline & & 4.3E06 & 2.103 & 3,583 & \\
\hline 15 & $\mathrm{SH}+\mathrm{OH} \rightleftharpoons \mathrm{S}+\mathrm{H}_{2} \mathrm{O}$ & $1.0 \mathrm{E} 13$ & 0.000 & 0 & [41] estimated \\
\hline 16 & $\mathrm{SH}+\mathrm{HO}_{2} \rightleftharpoons \mathrm{HSO}+\mathrm{OH}$ & $1.0 \mathrm{E} 12$ & 0.000 & 0 & [41] estimated \\
\hline 17 & $\mathrm{SH}+\mathrm{O}_{2} \rightleftharpoons \mathrm{SO}+\mathrm{OH}$ & $7.5 \mathrm{E} 04$ & 2.052 & 16,400 & {$[52]$} \\
\hline 18 & $\mathrm{SH}+\mathrm{O}_{2} \rightleftharpoons \mathrm{HSO}+\mathrm{O}$ & 2.3E06 & 1.816 & 20,000 & {$[52]$} \\
\hline \multirow[t]{2}{*}{19} & $\mathrm{SH}+\mathrm{O}_{2}(+\mathrm{M}) \rightleftharpoons \mathrm{HSOO}(+\mathrm{M})$ & $2.0 \mathrm{E} 14$ & -0.260 & 298 & \multirow[t]{2}{*}[53]{} \\
\hline & Low-pressure limit & 3.3E14 & -0.201 & 20 & \\
\hline 20 & $\mathrm{~S}+\mathrm{OH} \rightleftharpoons \mathrm{SO}+\mathrm{H}$ & $1.5 \mathrm{E} 13$ & 0.191 & $-1,361$ & {$[51]$} \\
\hline 21 & $\mathrm{~S}+\mathrm{O}_{2} \rightleftharpoons \mathrm{SO}+\mathrm{O}$ & 5.4E05 & 2.110 & $-1,450$ & [54] \\
\hline 22 & $\mathrm{SO}+\mathrm{M} \rightleftharpoons \mathrm{S}+\mathrm{O}+\mathrm{M}$ & 4.0E14 & 0.000 & 107,000 & {$[55]$} \\
\hline 23 & $\mathrm{SO}+\mathrm{H}+\mathrm{M} \rightleftharpoons \mathrm{HSO}+\mathrm{M}$ & $1.9 \mathrm{E} 20$ & -1.310 & 662 & {$[45]$} \\
\hline 24 & $\mathrm{SO}+\mathrm{O}+\mathrm{M} \rightleftharpoons \mathrm{SO}_{2}+\mathrm{M}$ & 4.1E22 & -2.170 & 0 & {$[56]$} \\
\hline 25 & $\mathrm{SO}+\mathrm{OH} \rightleftharpoons \mathrm{SO}_{2}+\mathrm{H}$ & $1.1 \mathrm{E} 17$ & -1.350 & 0 & [57] \\
\hline \multirow[t]{2}{*}{26} & $\mathrm{SO}+\mathrm{OH}(+\mathrm{M}) \rightleftharpoons \mathrm{HOSO}(+\mathrm{M})$ & $1.6 \mathrm{E} 12$ & 0.500 & -400 & \multirow[t]{2}{*}[58]{} \\
\hline & Low-pressure limit: & $9.5 \mathrm{E} 27$ & -3.480 & 970 & \\
\hline 27 & $\mathrm{SO}+\mathrm{HO}_{2} \rightleftharpoons \mathrm{SO}_{2}+\mathrm{OH}$ & 3.7E03 & 2.420 & 7,660 & {$[45]$} \\
\hline 28 & $\mathrm{SO}+\mathrm{O}_{2} \rightleftharpoons \mathrm{SO}_{2}+\mathrm{O}$ & $7.6 \mathrm{E} 03$ & 2.370 & 2,970 & [59] \\
\hline 29 & $\mathrm{OCS}_{2}+\mathrm{O} \rightleftharpoons \mathrm{OCS}+\mathrm{SO}$ & $6.0 \mathrm{E} 13$ & 0.000 & 0 & Estimated \\
\hline 30 & $\mathrm{OCS}_{2}+\mathrm{S} \rightleftharpoons \mathrm{OCS}+\mathrm{S}_{2}$ & $6.0 \mathrm{E} 13$ & 0.000 & 0 & {$[49]$} \\
\hline
\end{tabular}

Parameters for use in the modified Arrhenius expression $k=A T^{\beta} \exp (-E /[R T])$. Units are mol, $\mathrm{cm}, \mathrm{s}, \mathrm{cal}$.

${ }^{a}$ Duplicate reaction: The rate constant is calculated as the sum of the two Arrhenius expressions.

Saheb et al. [50]. The experimental results, which are captured well by the theoretical expression of Saheb et al., show that the reaction exhibits nonArrhenius behavior, and a direct extrapolation of the low-temperature results yields too small a rate constant at combustion conditions.

The reaction of OCS with atomic oxygen has been characterized experimentally in a wide range of temperature [65-76]. This work was reviewed thoroughly by Singleton and Cvetanovich [77], who found the measurements to be in good agreement and recommended kinetic parameters for the overall reaction for the temperature range $239-1900 \mathrm{~K}$. The OCS + O reaction has two product channels:

$$
\begin{aligned}
& \mathrm{OCS}+\mathrm{O} \rightleftharpoons \mathrm{CO}+\mathrm{SO} \\
& \mathrm{OCS}+\mathrm{O} \rightleftharpoons \mathrm{CO}_{2}+\mathrm{S}
\end{aligned}
$$

The dominant product channel at lower temperatures is (R3), whereas (R4) becomes more important with increasing temperature. There are only few data available for the branching fraction, defined here as 


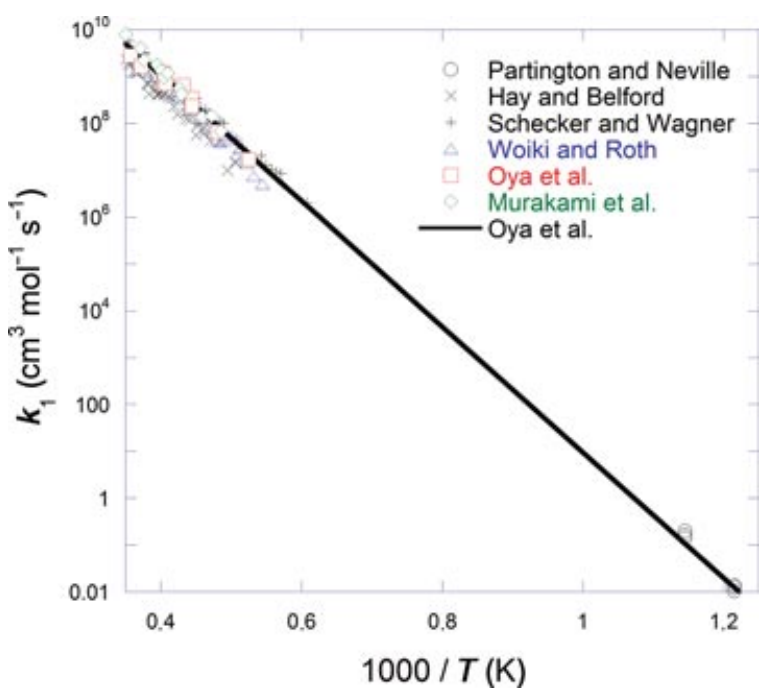

Figure 1 Arrhenius plot for the reaction $\mathrm{OCS}+\mathrm{M} \rightleftharpoons \mathrm{CO}+$ $\mathrm{S}+\mathrm{M}$. Experimental results (symbols) from Partington and Neville [23], Hay and Belford [25], Schecker and Wagner [26], Woiki and Roth [30], Oya et al. [32], and Murakami et al. [34]. The solid line denotes the recommendation of Oya et al., which is the preferred value in the present model.

$\alpha=k_{4} /\left(k_{3}+k_{4}\right)$. Figure 2 compares the reported data. Singleton and Cvetanovich based their evaluation of $k_{4}$ on the shock tube results of Topaluglu [76], covering the temperature range 1200-1900 K. Later, Isshiki et al. [78] determined $\alpha$ between 1120 and $1540 \mathrm{~K}$, reporting values significantly higher than those recommended by Singleton and Cvetanovich. The theoretical studies $[50,78,79]$ of the reaction are inconclusive regarding the branching fraction. Isshiki et al. performed quantum chemical calculations on this system with $\mathrm{G} 2 \mathrm{M}(\mathrm{CC} 1)$ and CCSD-based G3 methods. The rate coefficients they derived by using transition-state theory (TST) with Wigner tunneling corrections are much smaller than experimental values; in contrast, the predicted branching fraction is similar to their experimental values. Chiang et al. [79] argued that the failure of Isshiki et al. to predict the overall rate constant came from neglecting intersystem crossing from the triplet to the singlet surface. We comment that these crossings would have to occur with high probability to be important. Chiang et al. [79] note that at high temperatures the crossing becomes less important, and the Isshiki et al. calculation of $\alpha$ becomes more accurate. We note that the barriers obtained by Isshiki et al. with their G3type approach are ca. $2.4 \mathrm{kcal} \mathrm{mol}^{-1}$ below the G2M values they used for their kinetics calculations, and the G3 barriers might give better accord with experiment. Saheb et al. [50] explored the reaction by using various quantum chemical methods, with their most sophisti-

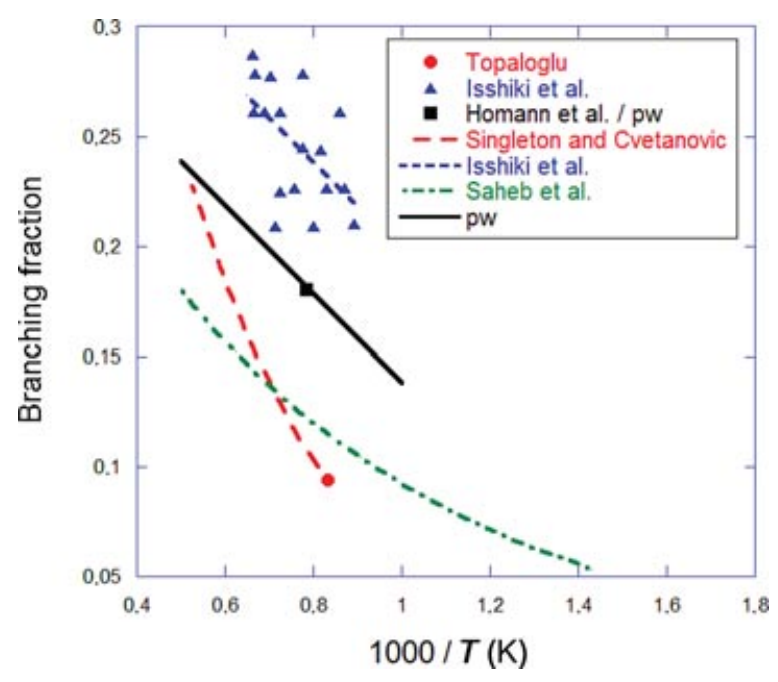

Figure 2 Arrhenius plot for the branching fraction $k_{3} /\left(k_{3}+k_{4}\right)$ for the reaction OCS + O. Experimental results (symbols) from Topaloglu [76], Isshiki et al. [78], and Homann et al. [24] (see text). "pw" denotes present work. The long-dashed line denotes the recommendation of Singleton and Cvetanovic [77], the dot-dashed line the calculated branching fraction from Saheb et al. [50], and the solid line the branching fraction used in the present model.

cated being W1BD, which also yielded lower barriers than derived by Chiang et al. TST was employed to calculate the thermal rate coefficients. Their calculations support the recommendation of Singleton and Cvetanovich, both for the overall rate and the branching ratio, without invoking intersystem crossing.

Owing to the significant scatter in the reported data for the branching fraction $\alpha$, we made an independent determination in the present work, based on the flow reactor results by Homann et al. [24]. As discussed in more detail below, Homann et al. measured concentration profiles of reactants and products as a function of time for a dry mixture of OCS and $\mathrm{O}_{2}$ in $\mathrm{Ar}$ at $1273 \mathrm{~K}$. Under these conditions, the $\mathrm{CO} / \mathrm{CO}_{2}$ ratio in the products is a measure of the relative importance of (R3) and (R4), since OCS is largely consumed by a reaction with $\mathrm{O}$, and $\mathrm{CO}$ oxidation will be very slow at dry conditions. We find $\alpha \approx 0.18$ at $1273 \mathrm{~K}$; a value roughly averaging the results of Singleton and Cvetanovich [77] and Isshiki et al. [78] at this temperature. We extrapolate this value to other temperatures assuming a temperature dependence similar to that reported by Isshiki et al. An accurate experimental determination of the branching fraction for OCS $+\mathrm{O}$ is desirable.

The reaction of OCS with $\mathrm{OH}$ is of interest in atmospheric chemistry and has been studied by a number of groups in the low-temperature range [80-86]. There is 
considerable scatter in these data. Atkinson et al. [3] based their recommendation on the work of Cheng and Lee [85] and Wahner and Ravishankara [86]. Theoretical studies $[50,87,88]$ have improved the understanding of the reaction. Saheb et al. [50] report that it has a pronounced pressure dependence at temperatures below $700 \mathrm{~K}$ where OCS and $\mathrm{OH}$ form an adduct. However, the pressure dependence is reduced at higher temperatures so that the reaction is nearly pressure independent at temperatures above $1500 \mathrm{~K}$. Under these conditions, the dominant product channel is $\mathrm{CO}_{2}+\mathrm{SH}$ :

$$
\mathrm{OCS}+\mathrm{OH} \rightleftharpoons \mathrm{CO}_{2}+\mathrm{SH}
$$

We adopt the rate constant for (R5) from Saheb et al. [50] and disregard formation of the adduct, which we believe will have a short lifetime under most practical conditions. Reaction (R5) has a significant barrier, and it is slower than other reactions of OCS with the $\mathrm{O} / \mathrm{H}$ radical pool.

Atomic sulfur, formed from dissociation of OCS at high temperature, reacts with OCS to form $\mathrm{CO}$ and $\mathrm{S}_{2}$ :

$$
\mathrm{OCS}+\mathrm{S} \rightleftharpoons \mathrm{CO}+\mathrm{S}_{2}
$$

This reaction is an important consumption step for OCS at higher temperatures, and it has been studied experimentally over a wide range of conditions [25,30,32,49,89-92]. We adopt the rate coefficients of Lu et al. [49]; their recommendation provides a good fit of available data over an extended temperature range. At high pressure and low temperatures, the OCS $+\mathrm{S}$ reaction may form a stabilized adduct:

$$
\mathrm{OCS}+\mathrm{S} \rightleftharpoons \mathrm{OCS}_{2}
$$

This channel was included in the model with the rate coefficients calculated by Lu et al. [49], but it is of minor importance under the conditions of the present study due to the low thermal stability of $\mathrm{OCS}_{2}$.

For reactions of OCS with $\mathrm{O}_{2}, \mathrm{SH}$, and $\mathrm{SO}$, there are no measurements available in the literature. All of these steps are presumably quite slow. We have included the reaction of OCS with $\mathrm{O}_{2}$ :

$$
\mathrm{OCS}+\mathrm{O}_{2} \rightleftharpoons \mathrm{CO}+\mathrm{SO}_{2}
$$

assuming that the rate constant is similar to that of $\mathrm{CS}_{2}+\mathrm{O}_{2}$. By analogy with (R5), we consider that the reaction of OCS with $\mathrm{SH}$ may yield $\mathrm{CS}_{2}$ and $\mathrm{OH}$ :

$$
\mathrm{OCS}+\mathrm{SH} \rightleftharpoons \mathrm{CS}_{2}+\mathrm{OH}
$$

We have estimated the rate constant to be similar to that of the $\mathrm{CO}_{2}+\mathrm{SH}$ reaction ( $\mathrm{R} 5 \mathrm{~b}$ ); this yields a value that is consistent with the measured room temperature upper limit for $\mathrm{CS}_{2}+\mathrm{OH}(\mathrm{R} 9 \mathrm{~b})[3,93]$. The reaction is very slow and can be disregarded under most conditions of interest. The reaction OCS $+\mathrm{SO}$ has two possible product channels:

$$
\begin{aligned}
& \mathrm{OCS}+\mathrm{SO} \rightleftharpoons \mathrm{CO}+\mathrm{S}_{2} \mathrm{O} \\
& \mathrm{OCS}+\mathrm{SO} \rightleftharpoons \mathrm{CS}+\mathrm{SO}_{2}
\end{aligned}
$$

Reaction (R10) is spin-forbidden. We assume that the transition state (TS) occurring on the triplet potential energy surface (PES) is the bottleneck for this step and that the intersystem crossing occurs on the downhill path toward $\mathrm{CO}+\mathrm{S}_{2} \mathrm{O}$. Even though (R10) is exothermic by $7.4 \mathrm{kcal} \mathrm{mol}^{-1}$, it is a slow reaction. At the CBS-QB3 level, the $0 \mathrm{~K}$ enthalpy of this triplet TS is $37.7 \mathrm{kcal} \mathrm{mol}^{-1}$ above OCS $+\mathrm{SO}$. For $k_{10}$, we use this value as the activation energy and estimate the $A$ factor by analogy to the spin-forbidden reaction $\mathrm{SO}+\mathrm{O}_{2}$. The channel to $\mathrm{CS}+\mathrm{SO}_{2}$ is endothermic by $27.7 \mathrm{kcal} \mathrm{mol}^{-1}$ and, we speculate, slower than (R10).

In the $\mathrm{S} / \mathrm{H} / \mathrm{O}$ subset of the mechanism, particularly the reactions of $\mathrm{S}$ and $\mathrm{SO}$ with $\mathrm{O}_{2}$ are important:

$$
\begin{array}{r}
\mathrm{S}+\mathrm{O}_{2} \rightleftharpoons \mathrm{SO}+\mathrm{O} \\
\mathrm{SO}+\mathrm{O}_{2} \rightleftharpoons \mathrm{SO}_{2}+\mathrm{O}
\end{array}
$$

Both of these reactions are characterized quite accurately over a wide temperature range [54,59].

\section{RESULTS AND DISCUSSION}

The available experimental data for thermal conversion of OCS are derived under pyrolysis or oxidation conditions. Data for thermal conversion of OCS in an inert atmosphere (pyrolysis), reported from batch reactors [23], flow reactors [5], and shock tubes $[25,26,30,32,34]$, were not considered for model validation in the present work. The results are consistent with the reaction sequence,

$$
\begin{array}{r}
\mathrm{OCS}+\mathrm{M} \rightleftharpoons \mathrm{CO}+\mathrm{S}+\mathrm{M} \\
\mathrm{OCS}+\mathrm{S} \rightleftharpoons \mathrm{CO}+\mathrm{S}_{2}
\end{array}
$$

and the rate constant for (R1), derived from the batch reactor $(823-873 \mathrm{~K})$ and shock tube work 
$(1500-3230 \mathrm{~K})$, is mostly in agreement within a factor of two (see Fig. 1). However, the flow reactor data obtained by Karan et al. [5] indicate an OCS consumption rate in the 1073-1223 K range that is too fast to be understood only in terms of the sequence of (R1) and (R7). The reason for the enhanced conversion rate for OCS under the conditions of Karan et al. is presently not known.

To evaluate the model, we have focused on oxidation of OCS, comparing predictions with experimental data for oxidation of OCS obtained in batch reactors [21,22], flow reactors [24], and shock tubes [28]. All these experiments were conducted under conditions with only trace amounts of water vapor. Levy and Merriman [38] reported detailed concentration profiles measured in low-pressure, laminar premixed OCS $/ \mathrm{O}_{2} / \mathrm{N}_{2}$ flames. They stated that addition of $0.2 \%$ $\mathrm{H}_{2} \mathrm{O}$ to the reactants did not affect the concentrations in the zone of OCS oxidation, but enhanced strongly the $\mathrm{CO}$ oxidation downstream. Unfortunately, we could not include these data in the model evaluation since insufficient details were given on the conditions of the flames.

\section{Explosion Limits}

To evaluate the performance of the chemical kinetic model at low temperatures, predictions have been compared to measured explosion limits in batch reactors at temperatures between 450 and $620 \mathrm{~K}$. Results have been reported by Bawn [20], Thompson et al. [21], and Gutschmidt and Clusius [22]. For comparison with modeling predictions, we have chosen the data from Thompson et al. [21] and Gutschmidt and Clusius [22], which are in good agreement.

The data reported are dependent on the surface to volume ratio of the reactor [22], and the (first) explosion limit is controlled mainly by competition between a gas-phase chain-branching reaction sequence and termination of radicals at the wall of the reactor. The experimental data chosen for comparison were obtained in reactors with diameters in the range $30-40 \mathrm{~mm}$. For modeling purposes, it is necessary to include a wall termination reaction. We assume that termination occurs by diffusion of atomic oxygen to the wall, followed by deactivation of the radical. The loss rate of $\mathrm{O}$ is approximated by a pseudo-first-order reaction, fitting the rate constant to match predictions for the limiting pressure at a temperature of $500 \mathrm{~K}$ to the experimental value of approximately $0.04 \mathrm{~atm}$. The loss rate constant is then extrapolated to other conditions, using the temperature and pressure dependence of the diffusion coefficient.

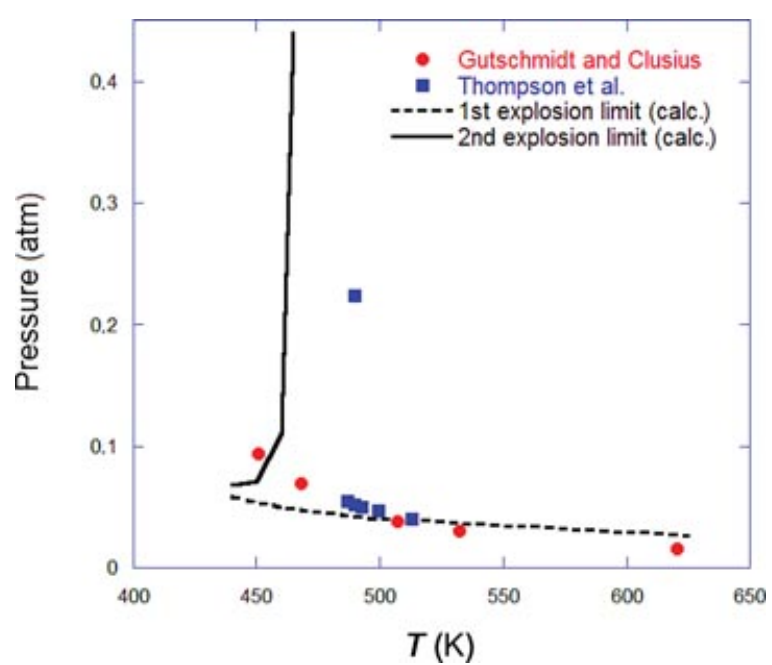

Figure 3 Comparison of experimental and predicted explosion limits for OCS in a batch reactor. The experimental data are taken from Thompson et al. [21], and Gutschmidt and Clusius [22]. The symbols mark experimental data, whereas solid and dashed lines denote model predictions. Inlet composition is $40 \%$ OCS, and $60 \% \mathrm{O}_{2}$. In the modeling, surface loss of atomic oxygen is modeled as a first-order reaction with the rate constant $\mathrm{k}_{\text {loss }}=4350 \cdot(0.04 \mathrm{~atm} / \mathrm{P})$. $(\mathrm{T} / 500 \mathrm{~K})^{1.5}\left(\mathrm{~s}^{-1}\right)$.

Figure 3 compares the measured and calculated explosion limits. The experimental results indicate the existence of a temperature range, located in the 450-500 $\mathrm{K}$ range, where there is both a lower and an upper critical pressure limit. The lower limit is only slightly dependent on temperature, whereas the upper limit would be expected to exhibit a stronger temperature dependence. Similar to the first limit, the second limit is controlled by a competition between chain-branching and chain-terminating reactions, but the second limit is generally not affected by surface reactions. Thompson et al. [21] report that the dependence of the second limit on pressure and temperature is uncertain and provide only one data point. However, they are convinced about the existence of the second limit, even though it may exist only in a narrow temperature range.

The agreement between the reported observations and the calculations is satisfactory. The model predicts correctly that the lower limit pressure at which explosion occurs has only a small dependence of temperature in the investigated range. Also, the lowtemperature limit for explosion, which according to the reported data is approximately $450 \mathrm{~K}$, is predicted well. Interestingly, the model also captures the existence of an upper critical pressure in a very narrow temperature range. 


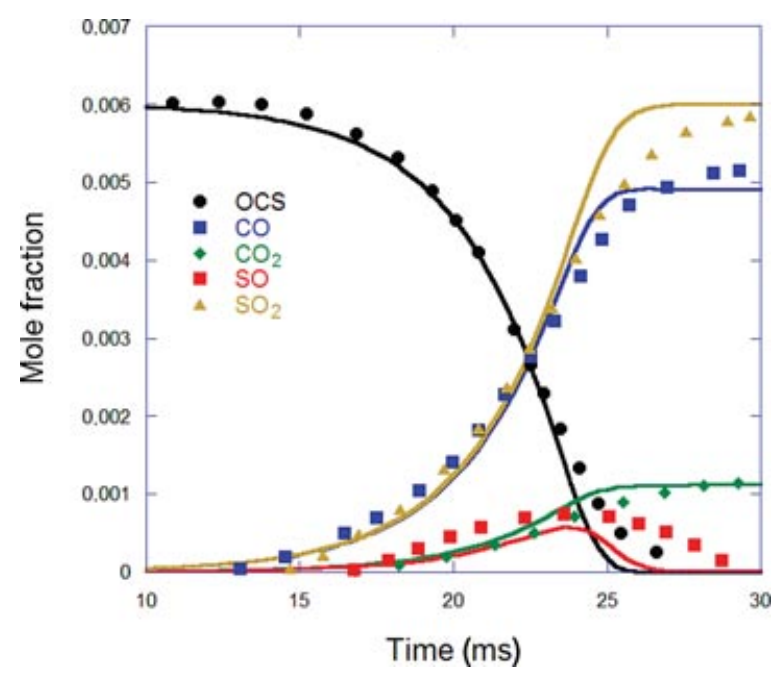

Figure 4 Comparison of experimental and predicted mole fractions for oxidation of OCS in a flow reactor at low pressure. The experimental data are taken from Homann et al. [24], as reported by Cullis and Mulcahy [16]. The symbols mark experimental data, whereas solid lines denote model predictions. Conditions: $T=1273 \mathrm{~K}, P=0.0566 \mathrm{~atm}$, inlet composition is $0.6 \% \mathrm{OCS}, 6.6 \% \mathrm{O}_{2}$, balance $\mathrm{Ar}$. In the comparison, the modeling predictions are shifted $2 \mathrm{~ms}$ to the left to match the observed time for $50 \%$ conversion of OCS.

\section{Oxidation in a Flow Reactor}

Homann et al. [24] reported detailed species measurements as a function of time (distance) in a low-pressure flow reactor. The data were obtained by molecular beam mass spectrometry. Homann et al. measured concentrations of $\mathrm{OCS}, \mathrm{CO}, \mathrm{CO}_{2}, \mathrm{SO}, \mathrm{SO}_{2}$, as well as a number of minor species, at a temperature of $1273 \mathrm{~K}$ and a pressure of $0.057 \mathrm{~atm}$. The experimental results are compared with modeling predictions in Fig. 4. In addition to the sulfur species shown, $\mathrm{S}, \mathrm{S}_{2}, \mathrm{~S}_{2} \mathrm{O}$, and $\mathrm{S}_{2} \mathrm{O}_{2}$ were also detected in small quantities. Homann et al. assumed that atomic oxygen was partly destroyed at the wall; however, such a reaction is not taken into consideration in the present modeling.

Figure 4 compares modeling predictions with the measured species profiles. In this comparison, we have chosen to shift the predicted concentration profiles to match the observed time for $50 \%$ conversion of OCS. From the description of the experimental setup [68], we assume that the reactants OCS and $\mathrm{O}_{2}$ were preheated separately and mixed at the entrance to the reaction zone. The mixing process of the reactants may affect the induction time of reaction, justifying this correction. However, a shift of only $2 \mathrm{~ms}$ serves to match the profiles at $50 \%$ conversion of OCS.

With the slight correction for the onset of reaction, the modeling predictions are in very good agreement

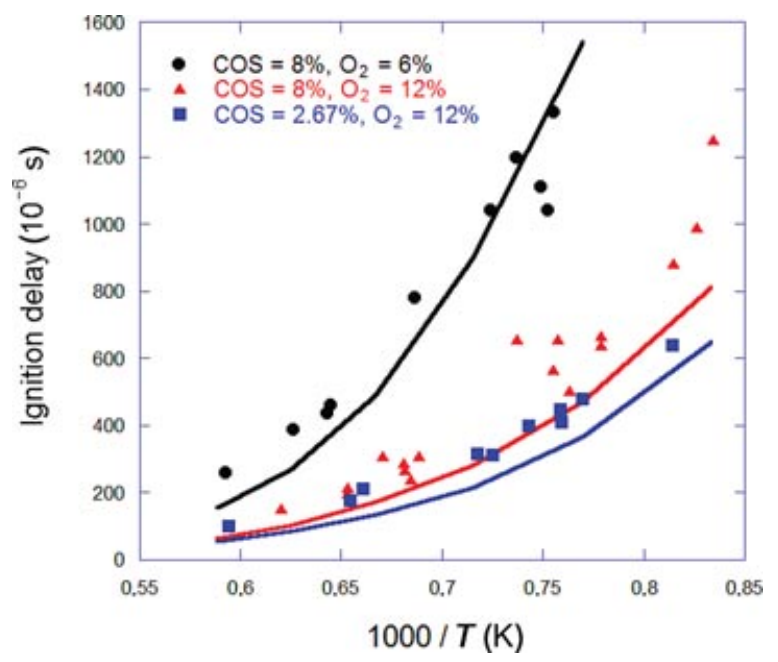

Figure 5 Comparison of experimental and predicted ignition delays for $\mathrm{OCS} / \mathrm{O}_{2} / \mathrm{Ar}$ mixtures. The experimental data are taken from Lifshitz et al. [28], obtained in reflected shock tube experiments. The symbols mark experimental data, whereas solid lines denote model predictions. The results were obtained for three fuel/oxidizer compositions. Initial pressure $P_{1}$ was 0.066 atm in all experiments. The pressure $P_{5}$ was calculated as $P_{5}(\mathrm{~atm})=2.55 \cdot 10^{-3} T(\mathrm{~K})-$ 1.3844 , based on a least squares regression of the listed values for the total concentration $C_{5}$ from Lifshitz et al.

with the measured concentration profiles of Homann et al. The major species are captured well by the model, and even for the SO radical the peak concentration is predicted within $20 \%$.

\section{Ignition Delay}

Lifshitz et al. measured ignition delays for $\mathrm{OCS} / \mathrm{O}_{2} / \mathrm{Ar}$ mixtures in a reflected shock tube as a function of temperature (1200-1700 K), pressure, and reactant composition. The time for ignition was determined from the pressure and temperature profiles.

Figure 5 compares experimental data with modeling predictions for three mixture compositions ranging from rich to lean. The results of Lifshitz et al. show that the ignition delay for OCS is a strong function of the temperature and oxygen concentration, while it has only a small dependence on the OCS concentration. Correlating all their data, Lifshitz et al. found $\tau_{\text {ign }}$ to be proportional to $[\mathrm{OCS}]^{-0.30}$ and $\left[\mathrm{O}_{2}\right]^{1.12}$. This is in agreement with the results shown in Fig. 5, where a change in $\left[\mathrm{O}_{2}\right]$ from $6 \%$ to $12 \%$ has a much larger impact than reducing [OCS] from $8 \%$ to $2.67 \%$.

The calculations are seen to be in good agreement with the experimental data, with the model predicting correctly the effect of temperature and stoichiometry. The model appears to underpredict slightly the 


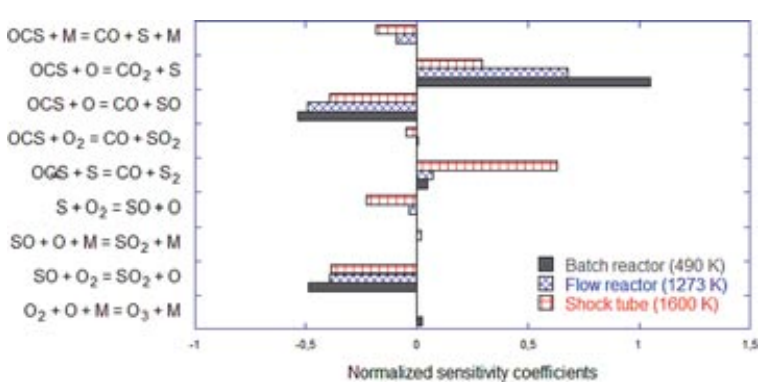

Figure 6 Sensitivity coefficients for the induction time at different reaction conditions. The coefficients show the relative change in the predicted induction time caused by a factor of two increase in the rate constant of the specific reaction. Conditions correspond to those of the experiments conducted in a batch reactor (Fig. 3, $490 \mathrm{~K}, 0.224 \mathrm{~atm}$ ), flow reactor (Fig. 4, $1273 \mathrm{~K}, 0.0566 \mathrm{~atm}$ ), and shock tube (Fig. 5, $1600 \mathrm{~K}, 2.7 \mathrm{~atm})$.

ignition delay, but the difference is probably within the experimental uncertainty.

\section{Reaction Paths and Bottlenecks}

In this section, we discuss the oxidation pathways for OCS and identify the reactions that are rate limiting for the oxidation rate. Figure 6 shows the results of a sensitivity analysis for selected experimental conditions.

The analysis of the calculations with the model shows that the same set of key reactions plays an important role over the range of conditions investigated, from the low-temperature batch reactor experiments to the high-temperature shock tube experiments. The key reactions involve the chain-propagating sequence $(\mathrm{P})$,

$$
\begin{aligned}
& \mathrm{OCS}+\mathrm{O} \rightleftharpoons \mathrm{CO}+\mathrm{SO} \\
& \mathrm{SO}+\mathrm{O}_{2} \rightleftharpoons \mathrm{SO}_{2}+\mathrm{O},
\end{aligned}
$$

$$
\mathrm{OCS}+\mathrm{O}_{2} \rightleftharpoons \mathrm{CO}+\mathrm{SO}_{2}
$$

and the chain-branching sequence (B),

$$
\begin{gathered}
\mathrm{OCS}+\mathrm{O} \rightleftharpoons \mathrm{CO}_{2}+\mathrm{S} \\
\mathrm{S}+\mathrm{O}_{2} \rightleftharpoons \mathrm{SO}+\mathrm{O} \\
\mathrm{SO}+\mathrm{O}_{2} \rightleftharpoons \mathrm{SO}_{2}+\mathrm{O} \\
\mathrm{OCS}+2 \mathrm{O}_{2} \rightleftharpoons \mathrm{CO}+\mathrm{SO}_{2}+\mathrm{O}
\end{gathered}
$$

The propagating and branching sequences compete with terminating steps that are specific for the type of reactor and the temperature/pressure range of the experiment.

Under the conditions of the batch reactor experiments (450-620 K), the ignition delay and explosion limits are controlled by the competition of the $(\mathrm{P})$ and (B) sequences with chain termination. The terminating reaction depends on the pressure. At the lower limiting pressure, termination is dominated by radical diffusion to the wall and subsequent deactivation:

$$
\mathrm{O} \stackrel{+ \text { wall }}{\longrightarrow} \text { inert }
$$

At approximately $450 \mathrm{~K}$ and increased pressure, the model also predicts an upper limiting pressure. This explosion limit is controlled by a gas-phase termination sequence:

$$
\begin{gathered}
\mathrm{O}_{2}+\mathrm{O}+\mathrm{M} \rightleftharpoons \mathrm{O}_{3}+\mathrm{M} \\
\mathrm{O}_{3}+\mathrm{O} \rightleftharpoons \mathrm{O}_{2}+\mathrm{O}_{2}
\end{gathered}
$$

Only the first of these steps, the $\mathrm{O}_{2}+\mathrm{O}$ recombination, shows up in the sensitivity analysis, as the $\mathrm{O}_{3}+\mathrm{O}$ reaction is fast.

Despite the large sensitivity coefficients for the two OCS + O product channels (Fig. 6), it is not possible to estimate a value of the branching fraction $\alpha$ from the observed explosion limits. This is due to the uncertainty in the wall termination rate (the first explosion limit) and in the limiting pressure and temperature (the second explosion limit).

For the flow reactor conditions corresponding to the experiments of Homann et al. (Fig. 4), the mechanisms of chain propagation (P) and branching (B) are the same as for the low-temperature batch experiments. The temperature of $1273 \mathrm{~K}$ in the flow reactor is sufficiently high for thermal dissociation of OCS

$$
\mathrm{OCS}+\mathrm{M} \rightleftharpoons \mathrm{CO}+\mathrm{S}+\mathrm{M}
$$

to promote ignition, and it appears in the sensitivity analysis. The reaction of OCS with $\mathrm{O}_{2}$

$$
\mathrm{OCS}+\mathrm{O}_{2} \rightleftharpoons \mathrm{CO}+\mathrm{SO}_{2}
$$

is not important as an initiation step, because $\mathrm{CO}$ is largely inert under the conditions of the flow reactor experiments with only trace amounts of water vapor.

We have used the data from Homann et al. to estimate the OCS + O branching fraction at $1273 \mathrm{~K}$. As discussed above, the determination was based on the 
measured $\mathrm{CO} / \mathrm{CO}_{2}$ in the products. However, the predicted time for onset of reaction is also very sensitive to $\alpha$. The value of the branching fraction that yields the best agreement for the ignition delay under these conditions (disregarding any influence of mixing) is $\alpha=0.19$; very close to the value of 0.18 determined from the $\mathrm{CO} / \mathrm{CO}_{2}$ ratio.

The modeling of the shock tube experiments (Fig. 5) allows us to extend the analysis to temperatures of $1700 \mathrm{~K}$. Again, ignition is promoted by the chainbranching sequence (B) and inhibited by the chainpropagating sequence $(\mathrm{P})$. At the high temperatures, the reaction of OCS with atomic sulfur,

$$
\mathrm{OCS}+\mathrm{S} \rightleftharpoons \mathrm{CO}+\mathrm{S}_{2}
$$

also becomes important as a chain terminating step. Reaction (R7) is the step that exhibits the largest sensitivity coefficients for the shock tube calculations (Fig. 6). However, three independent studies of this step in the $1200-1700 \mathrm{~K}$ range $[32,91,92]$ are in excellent agreement and we expect the uncertainty in the modeling predictions for oxidation of OCS at high temperatures to be mainly related to the uncertainty in the $\mathrm{OCS}+\mathrm{O}$ branching fraction.

\section{CONCLUSIONS}

A detailed chemical kinetic model for oxidation of OCS has been developed and validated against experimental results from batch reactors, flow reactors, and shock tubes. All the selected experimental data were obtained under conditions with only trace amounts of water vapor. However, reported data from premixed flames indicate that larger levels of $\mathrm{H}_{2} \mathrm{O}$ enhance oxidation of $\mathrm{CO}$ to $\mathrm{CO}_{2}$, but do not affect the OCS consumption rate. The model predicts satisfactorily oxidation of OCS over a wide range of stoichiometry, temperature, and pressure. The governing reactions for oxidation of OCS are outlined based on calculations with the kinetic model. The oxidation rate of OCS is controlled by the competition between chainbranching and -propagating steps; modeling predictions are particularly sensitive to the branching fraction for the OCS $+\mathrm{O}$ reaction to form $\mathrm{CO}+\mathrm{SO}$ or $\mathrm{CO}_{2}+\mathrm{S}$.

PM thanks the R.A. Welch Foundation (grant B-1174) for support and the National Science Foundation (grant CHE0741936) for purchase of computational facilities.

\section{BIBLIOGRAPHY}

1. Johnsson, J. E.; Glarborg, P. In Pollutants from Combustion, Vovelle, C. Ed.; Kluwer: Boston, MA 2000; pp. 263-282.

2. Monnery, W. D.; Svreck, W. Y.; Behie, L. A. Can J Chem Eng 1993, 71, 711-724.

3. Atkinson, R.; Baulch, D. L.; Cox, R. A.; Crowley, J. N.; Hampson, R. F.; Hynes, R. G.; Jenkin, M. E.; Rossi, M. J.; Troe, J. Atmos Chem Phys 2004, 4, 1461-1738.

4. Clark, P. D.; Dowling, N. I.; Huang, M.; Svreck, W. Y.; Monnery, W. D. Ind Eng Chem Res 2001, 40, 497-508.

5. Karan, K.; Mehrotra, A. K.; Behie, L. A. Chem Eng Commun 2005, 192, 370-385.

6. Karan, K.; Mehrotra, A. K.; Behie, L. A. Chem Eng Sci 1999, 54, 2999-3006.

7. Karan, K.; Mehrotra, A. K.; Behie, L. A. Can J Chem Eng 1999, 77, 392-398.

8. Gargurevich, I. A. Ind Eng Chem Res 2005, 44, 77067729.

9. Kaloidas, V.; Papayannakos, N. Chem Eng Sci 1989, 44, 2493-2500.

10. Harvey, W. S.; Davidson, J. H.; Fletcher, E. A. Ind Eng Chem Res 1998, 37, 2323-2332.

11. Shiina, K.; Miyoshi, A.; Matsui, H. J Phys Chem A 1998, 102, 3556.

12. Karan, K.; Mehrotra, A. K.; Behic, L. A. AIChE J 1999, 45, 383-389.

13. Hawboldt, K. A.; Monnery, W. D.; Svrcek, W. Y. Chem Eng Sci 2000, 55, 957-966.

14. Sendt, K.; Jazbec, M.; Haynes, B. S. Proc Combust Inst 2002, 29, 2439-2446.

15. Binoit, M.; Labegorre, B.; Monnet, F.; Clarke, P. D.; Dowling, N. I.; Huang, M.; Archambault, D.; Plasari, E.; Marquaire, P.-M. Ind Eng Chem Res 2003, 42, 3943 3951.

16. Cullis, C. F.; Mulcahy, M. F. R. Combust Flame 1972 , 18, 225-292.

17. Jazbec, M.; Sendt, K.; Haynes, B. S. Fuel 2004, 83, 2133-2138.

18. Shen, L. H.; Wu, J. H.; Gao, Z. P.; Xiao, J. Combust Flame 2010, 157, 934-942.

19. Wang, X. B.; Si, J. P.; Tan, H. Z.; Ma, L.; Pourkashanian, M.; Xu, T. M. Energy Fuels 2010, 24, 5215-5221.

20. Bawn, C. E. H. J Chem Soc 1933, 145.

21. Thompson, H. W.; Hovde, F. L.; Cairns, A. C. H. J Chem Soc 1933, 208.

22. Gutschmidt, H.; Clusius, K. Z Phys Chem B 1935, 30, 265-279.

23. Partington, J. R.; Neville, H. H. J Chem Soc London 1951, 23, 1230-1237.

24. Homann, K. H.; Krome, G.; Wagner, H. G. Ber Bunsen Phys Chem 1969, 73, 967-971.

25. Hay, A. J.; Belford, R. L. J Chem Phys 1967, 47, 3944.

26. Schecker, H. G.; Wagner, H.Gg. Int J Chem Kinet 1969, 1,541 .

27. Sheen, D. B. J Chem Phys 1970, 52, 648. 
28. Lifshitz, A.; Frenklach, M.; Schechner, P.; Carroll, H. F. Int J Chem Kinet 1975, 7, 753-773.

29. Saito, K.; Ueda, Y.; Ito, R.; Kakumoto, T.; Imamura, A. Int J Chem Kinet 1986, 18, 871-884.

30. Woiki, D.; Roth, P. Ber Bunsen-Ges Phys Chem 1992, 96, 1347-1352.

31. Woiki, D.; Roth, P. Int J Chem Kinet 1995, 27, 59-71.

32. Oya, M.; Shiina, H.; Tsuchiya, K.; Matsui, H. Bull Chem Soc Jpn 1994, 67, 2311-2313.

33. Miyoshi, A.; Shiina, H.; Tsuchiya, K.; Matsui, H. Proc Combust Inst 1996, 26, 535-541.

34. Murakami, Y.; Kosugi, M.; Susa, K.; Kobayashi, T.; Fujii, N. Bull Chem Soc Jpn 2001, 74, 1233-1240.

35. Chamberlain, D. S.; Clarke, D. R. Ind Eng Chem 1928, 20, 1016

36. Sarkisyan, E. N.; Nalbandyan, A. B. Dokl Akad Nauk 1968, 178, 69 (English version).

37. Azatyan, V. V.; Gershenzon, Y. M.; Sarkisyan, E. N.; Sachyan, G. A.; Nalbandyan, A. B. Proc Combust Inst 1969, 12, 969.

38. Levy, A.; Merryman, E. L.; Env Sci Technol 1969, 3, 63.

39. Levy, A.; Merryman, E. L.; Proc Combust Inst 1971, 13, 427

40. Rasmussen, C. L.; Hansen, J.; Marshall, P.; Glarborg, P. Int J Chem Kinet 2008, 40, 454-480.

41. Glarborg, P.; Kubel, D.; Dam-Johansen, K.; Chiang, H.M.; Bozzelli, J. W. Int J Chem Kin 1996, 28, 773-790.

42. Alzueta, M. U.; Bilbao, R.; Glarborg, P. Combust Flame 2001, 127, 2234-2251.

43. Dagaut, P.; Lecomte, F.; Mieritz, J.; Glarborg, P. Int J Chem Kinet 2003, 35, 564-575.

44. Glarborg, P. Proc Combust Inst 2007, 31, 77-98.

45. Rasmussen, C. L.; Glarborg, P.; Marshall, P. Proc Combust Inst 2007, 31, 339-347.

46. Jørgensen, T. L.; Livbjerg, H.; Glarborg, P. Chem Eng Sci 2007, 62, 4496-4499.

47. Hindiyarti, L.; Glarborg, P.; Marshall, P. J Phys Chem A 2007, 111, 3984-3991.

48. E. Goos; A. Burcat, and B. Ruscic. Ideal gas thermochemical database with updates from active thermochemical tables (ftp://ftp.technion.ac.il/pub/supported/ aetdd/thermodynamics; mirrored at http://garfield. chem.elte.hu/burcat/burcat.html. Accessed October 2012.

49. Lu, C.-W.; Wu, Y.-J.; Lee, Y.-P.; Zhu, R. S.; Lin, M. C. J Chem Phys 2006, 125, 164329.

50. Saheb, V.; Alizadeh, M.; Rezaei, F.; Shahidi, S. Comput Theor Chem 2012, 994, 25-33.

51. Sendt, K.; Haynes, B. S. Proc Combust Inst 2007, 31, 257-265.

52. Zhou, C. R.; Sendt, K.; Haynes, B. S. J Phys Chem A 2009, 113, 2975-2981.

53. Goumri, A.; Rocha, J.-D. R.; Marshall, P. J Phys Chem 1995, 99, 10834.

54. Lu, C.-W.; Wu, Y.-J.; Lee, Y.-P.; Zhu, R. S.; Lin, M. C. J Chem Phys 2004, 121, 8271.

55. Plach, H. J.; Troe, J. Int J Chem Kinet 1984, 16, 1531.
56. Lu, C.-W.; Wu, Y.-J.; Lee, Y.-P.; Zhu, R. S.; Lin, M. C. J Phys Chem A 2003, 107, 11020-11029.

57. Blitz, M. A.; McKee, K. W.; Pillling, M. Proc Combust Inst 2000, 28, 2491-2497.

58. A. Goumri, A.; Rocha, J.-D.; Laakso, D.; Smith, C. E.; Marshall, P. J Phys Chem A 1999, 103, 11328-11335.

59. Tsuchiya, K.; Kamiya, K.; Matsui, H. Int J Chem Kinet 1997, 29, 57-66.

60. Rommel, H.; Schiff, H. I. Int J Chem Kinet 1972, 4, 547-558.

61. Tsunashima, S.; Yokota, T.; Safarik, I.; Gunning, H. E.; Strausz, O. P. J Phys Chem 1975, 79, 775-778.

62. Lee, J. H.; Stief, L. J.; Timmons, R. B. J Chem Phys 1977, 67, 1705-1709.

63. Woiki, D.; Roth, P. Israel J Chem 1996, 36, 279-283.

64. Rice, B. M.; Pai, S. V.; Chabalowski, C. F. J Phys Chem 1998, 35, 6950-6956.

65. Sullivan, J. O.; Warneck, P. Ber Bunsenges Phys Chem 1965, 69, 7.

66. Hoyermann, K.; Wagner, H.Gg.; Wolfrum, J Ber Bunsen Phys Chem 1967, 71, 603-606.

67. Westenberg, A. A.; De Haas, N. J Chem Phys 1969, 50, 7019-7077.

68. Homann, K. H.; Krome, G.; Wagner, H.Gg. Ber Bunsen Phys Chem 1968, 72, 998-1004.

69. Krezenski, D. C.; Simonaitis, R.; Heicklen, J. Int J Chem Kinet 1971, 3, 467-482.

70. Breckenridge, W. H.; Miller, T. A. J Chem Phys 1972, 56, 465-474.

71. Klemm, R. B.; Stief, L. J. J Chem Phys 1974, 61, 49004906.

72. Wei, C. N.; Timmons, R. B. J Chem Phys 1975, 62, 3240-3245.

73. Manning, R. G.; Braun, W.; Kurylo, M. J. J Chem Phys 1976, 65, 2609.

74. Yoshida, N.; Saito, S. Bull Chem Soc Jpn 1978, 51, 1635.

75. Robertshaw, J. S.; Smith, I. W. M. Int J Chem Kinet 1980, 12, 729.

76. Topaluglu, T. Diss Abst Int B 1982, 42, 4134.

77. Singleton, D. L.; Cvetanovic, R. J. J Phys Chem Ref Data 1988, 17, 1377-1437.

78. Isshiki, N.; Murakami, Y.; Tsuchiya, K.; Tezaki, A.; Matsui, H. J Phys Chem A 2003, 107, 2464-2469.

79. Chiang, H.-C.; Wang, N.-S.; Tsuchiya, S.; Chen, H.T.; Lee, Y.-P.; Lin, M. C. J Phys Chem A 2009, 113, 13260-13272.

80. Atkinson, R.; Perry, R. A.; Pitts Jr., J. N. Chem Phys Lett 1978, 54, 14-18.

81. Kurylo, M. J. Chem Phys Lett 1978, 58, 238-242.

82. Cox, R. A.; Sheppard, D. Nature (London) 1980, 284, 330-331.

83. Ravishankara, A. R.; Kreutter, N. M.; Shah, R. C.; Wine, R. H. Geophys Res Lett 1980, 7, 861-864.

84. Leu, M. T.; Smith, R. H. J Phys Chem 1981, 85, 25702575.

85. Cheng, B. M.; Lee, Y. P. Int J Chem Kinet 1986, 18, 1303-1314. 
86. Wahner, A.; Ravishankara, A. R. Geophys Res 1987 , 92, 2189-2194.

87. Wilson, C.; Hirst, D. M. Chem Soc Faraday Trans 1995, 91, 793-798.

88. Danielache, S. O.; Johnson, M. S.; Nanbu, S.; Grage, M. M. L.; McLinden, C.; Yoshida, N. Chem Phys Lett 2008, 450, 214-220.

89. Jakubowski, E.; Ahmed, M. G.; Lown, E. M.; Sandhu, H. S.; Gosavi, R. K.; Strausz, O. P. J Am Chem Soc 1972, 94, 3944.
90. Klemm, R. B.; Davis, D. D. J Phys Chem 1974, 78, 1137.

91. Woiki, D.; Markus, M. W.; Roth, P. J Phys Chem 1993, 97, 9682-9685.

92. Shiina, H.; Oya, M.; Yamashita, K.; Miyoshi, A.; Matsui, H. J Phys Chem 1996, 100, 21362140.

93. Murrells, T. P.; Lovejoy, E. R.; Ravishankara, A. R. J Phys Chem 1990, 94, 23812386. 